\title{
Safe Construction Works Made of Reliable Construction Products based on verified structural calculations
}

\author{
G. Breitschaft ${ }^{1}$ \\ ${ }^{1}$ President of DIBt (German Institute of Construction Engineering), Berlin, Germany
}

\begin{abstract}
Ensuring the safety of buildings and other construction works is a major public concern. This article gives an overview of the mechanisms and structures put in place in Europe, and more specifically Germany, to ensure safety in construction. The article identifies major risk factors and shows how the European and German governmental and private systems respond to these risks. The questions addressed include: How do regulators ensure the use of safe construction products and designs, and how is the execution of construction works monitored?
\end{abstract}

\section{Introduction}

Safety in construction is a key issue for all societies in the world. We want to be sure that our life and health are safe when we enter a building, pass over a bridge or use a street.

However, it is impossible to make construction works $100 \%$ safe. This is why each society has to define the level of risk it is prepared to accept. The individual levels of risk vary from one country to another and also strongly depend on economic factors.

Construction works consist of numerous products assembled using manpower and (often) machines. In order to ensure the safety of construction works, the construction products used need to guarantee a certain performance level over time. Also, the construction techniques used need to meet certain minimum standards as well as structural calculations.Establishing and running good quality systems is always expensive, however, rebuilding a collapsed building is much more costly - not to mention the value of people's lives and health.

\section{Ensuring the use of reliable construction products}

In Germany and in most other European countries, construction products usually need to comply with a standard or another technical specification ("standardised products") before being incorporated into construction works.

"Non-standardised products" generally may not be used. The manufacturer of the construction product has to affix a marking to the product itself or the accompanying documents, indicating which technical specification has been used. In Germany, products complying with the national technical specifications bear the Ü mark (from "Übereinstimmung", the German for "conformity") while products complying with European technical specifications bear the $\mathrm{CE}$ marking. At a national level, the applicable rules are laid down in the Building Codes of the German federal states, and at a European level, they are set out in the Construction Products Regulation [1]. The national and European legal frameworks must not conflict. In case of doubt, European law prevails.

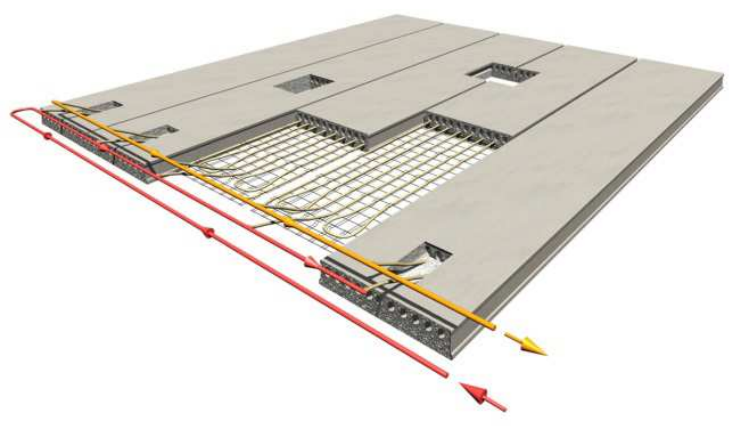

Fig. 1. Technical specifications are used to ensure the reliability of construction products, e.g. in prestressed hollow core slabs (source: Forschungsgesellschaft VMM Spannbetonplatten GbR, Kerpen)

\subsection{Technical specifications}

Technical specifications are mostly standards, which are developed by European standards organisations. If there is no standard, which is often the case for innovative products, approvals or technical assessments are used. These can only be issued by technical assessment bodies specially recognised for this purpose. For individual projects, it is often possible to apply for a special authorisation with the local authorities. Technical specifications define certain product characteristics and the (test or calculation) methods used in order to assess the 
performance levels achieved for these characteristics. The technical specifications also contain requirements relating to the production process to ensure that the performance level remains constant over time.

\subsubsection{Standards}

Most European countries each have one main standards organisation. Standards organisations are usually private sector institutions funded by the industry. Selling the finalised standards is an important source of their financing. However, many of these organisations are still linked to the public authorities via different agreements. New standards projects are usually put forward by industrial stakeholders, but they can also be initiated by public institutions. For example, the European Commission has mandated (and partly financed) the development of all harmonised European standards for construction products. Standards organisations are expected to give all relevant stakeholders the opportunity to participate equally and fairly in the preparation of a standard. The European Committee for Standardization CEN brings together the national standards organisations in Europe.

In addition to the big standards organisations, there are smaller private or public organisations involved in developing technical specifications for speciality areas - usually calling these "guidelines" or "rules" instead of standards.

\subsubsection{Approvals and technical assessments}

In Germany, if there is no standard (yet), there are two options. The manufacturer can either apply for a national technical approval, or he can apply for a European Technical Assessment (ETA). ETAs are issued on the basis of European Assessment Documents (EADs) which constitute the relevant technical specifications. In other words, within the European legal framework, the EAD sets out the applicable test methods, while the ETA contains the assessment of an individual construction product. With German national technical approvals, both aspects - the technical specification (test methods to be used) and the assessment of the test results - are combined in one document.

The Technical Assessment Bodies entitled to issue ETAs have to be designated by the Member States of the European Union. Germany has designated one single body: DIBt. In total, there are 47 Technical Assessment Bodies across Europe. Some of these bodies are public institutions, like DIBt; others are private sector organisations. An approval or ETA is only issued at the request of the manufacturer, who also has to bear the cost for drafting the document.

\subsection{Ensuring the constancy of performance of construction products}

Initial testing in accordance with a technical specification is like a snapshot: it certifies that a construction product showed a certain performance at a certain point in time. However, there is also a need for mechanisms to ensure that product performance remains constant over time. Depending on the impact of the construction product on the safety of the building and the risks associated with product failure, more or less stringent assessment systems apply. To clarify, these systems are not designed to assess the durability of construction products once incorporated into the works, but to monitor the manufacturing process. The aim is to make sure that products continue to display the same performance characteristics - let's say two years after the original assessment. In the simplest case, it is left to the manufacturer to ensure the constancy of performance. In this event, the manufacturer simply declares that his products permanently comply with the requirements set out in the technical specification. He also has to implement a production control system called factory production control.

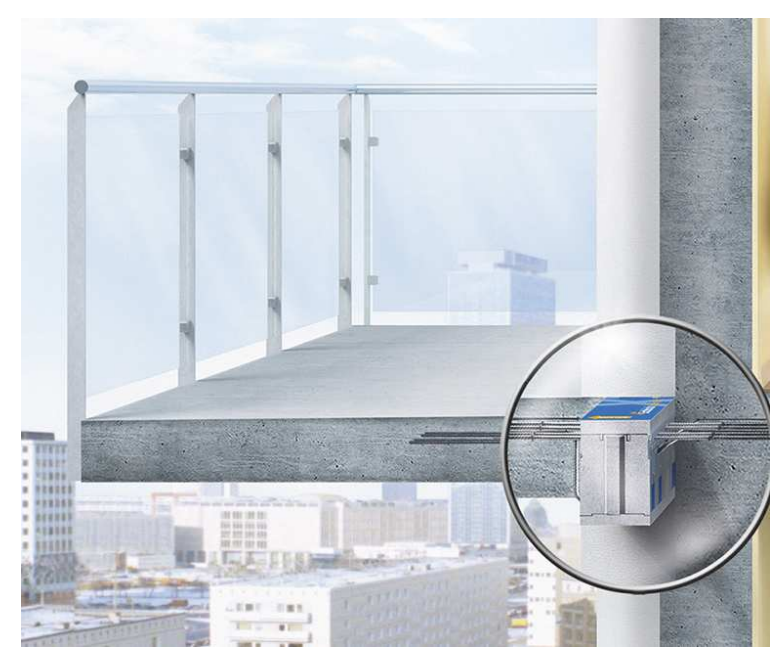

Fig. 2. Example of a highly safety-relevant product (balcony connector; source: Schöck Bauteile GmbH,Baden-Baden)

For highly safety-relevant construction products, the most stringent system applies, meaning that an independent body has to take samples from the production at regular intervals and verify compliance with the technical specification. Furthermore, an independent body has to monitor the factory production control implemented by the manufacturer. In between these extremes, the other systems combine the features outlined above in different ways. It is the task of the public authorities to determine which assessment system applies to which construction product. For products governed by European law, the European Commission determines the applicable system. For products governed by German law, this decision is taken by the national building authorities. The independent testing laboratories and certification bodies involved in the monitoring process have to comply with stringent requirements themselves, and prove their competence 
and independence. Furthermore, they need to be recognised by a public body. In Germany, DIBt is mandated to recognise these bodies. The manufacturers have to cover the costs for the constancy of performance assessment. The independent testing laboratories and certification bodies have to bear the costs for recognition.

\subsection{Market surveillance}

By affixing the $\mathrm{CE}$ marking to a product or the accompanying documents, the manufacturer guarantees that his product meets the requirements set out in the technical specification and that the constancy of performance assessment has duly been carried out.

The marking allows the contractor, the owner or the site manager to easily determine which construction products may be used on site, and according to which specifications and provisions these products have been manufactured and monitored. Products without such marking may not be stored on site or incorporated into construction works. The marking also gives information about the product's performance characteristics.

To avoid abuse or incorrect use of the marking, a market surveillance system has been put into place as an additional control mechanism. The purpose of market surveillance is to check whether the construction products placed on the market really have the product performance characteristics shown in the marking. Market surveillance is a public responsibility carried out by the authorities. In Germany, DIBt acts as the joint market surveillance authority of the German federal states.

The products and the accompanying documents may be checked at the manufacturing plant, in stores or in transit. The first step is to check if the documents and/or the marking show any evident formal shortcomings. In cases of suspected irregularities, product samples are taken and tested (e.g. for strength, reaction to fire behaviour or environmental effects).

In Europe, a differentiation is made between "active" and "reactive" market surveillance. Active market surveillance means that the market surveillance authorities carry out random checks in accordance with a previously established market surveillance programme. This, however, often only leads to the detection of clerical or formal errors.

Reactive market surveillance means that the market surveillance authorities follow up reports on suspicious products received from competitors or complaints received after an incident. Reactive market surveillance has proved an effective way of detecting fraud. The fraudulent party is liable to sanctions and fines.

The costs incurred by market surveillance measures are covered by the state, as long as the economic operator acted in good faith. However, if a manufacturer, importer or distributor is found to have acted fraudulently, he will have to pay the entire costs and additionally a fine, where applicable.

\section{Ensuring reliable design and execution}

Apart from ensuring the use of reliable construction products, regulators also have to ensure that the planning, design and construction of buildings and other works meet certain quality standards. During the planning stage, special attention needs to be paid to how the different products interact. As there is no harmonised European legislation in this field, different control mechanisms and measures have been implemented across Europe to ensure the safety of construction works. These systems vary considerably from one country to another. Below, I will therefore focus on the German regulatory system.

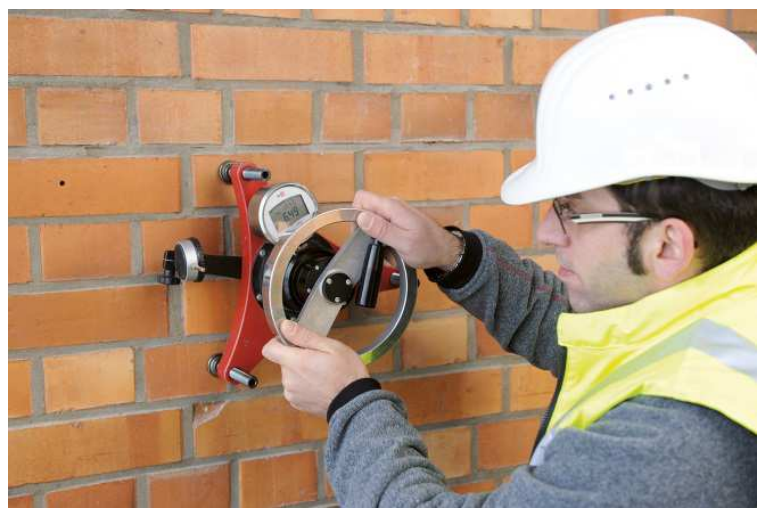

Fig. 3.Example of tests to be carried out on construction works (source: Adolf Würth GmbH \& Co. KG, Künzelsau)

\subsection{Ensuring a reliable structural design}

There is a comprehensive range of design standards to cover all types of construction works. The main set of structural design standards are the Eurocodes. This set of European standards covers all common types of construction: concrete, steel, composite steel and concrete, aluminium, timber, masonry and geotechnical design as well as general principles of structural design (including elements of safety theory), actions on structures and seismic design. The Eurocodes contain what are called "nationally determined parameters (NDPs)" to account for different local conditions. These nationally determined parameters are specified in National Annexes to the Eurocodes and are also published as standards. The use of the Eurocodes is mandatory in Germany.

In addition to the Eurocodes, there are several other relevant standards and guidelines in Germany relating, amongst other things, to wind turbines, chimneys, belfries and glass structures. The German building authorities regularly publish lists containing those standards and technical rules which designers and planners should use to ensure safe building. If designers or planners wish to deviate from these technical rules, they have to convince the building authorities that the rules they wish to apply are at 
least equivalent to the ones in the official lists (which is not an easy thing to do). If an economic operator wishes to establish a non-standardised design, e.g. a structural design using innovative building materials, he needs to apply to DIBt for approval. Other European Countries use a "voluntary" system. Here, it is not the authorities which require an approval but the insurance companies. In order to get good insurance conditions, the buildings have to comply with certain national specifications.

Structural designs may only be elaborated by experienced structural engineers who need to prove their technical expertise in order to have their names put on special lists kept by the construction industry chambers. Professional liability insurance is mandatory. Additionally, structural calculations and drawings of complex or critical constructions have to be verified by a "certified structural engineer". Certified structural engineers have to demonstrate extended knowledge and experience and pass a public examination. Certified structural engineers are commissioned either by the owner or by the building authorities. The verification services have to be paid for by the owner.

\subsection{Ensuring reliable execution of construction works}

There are also many standards, guidelines and codes of good practice relating to the execution of construction works. These rules are elaborated by the European Committee for Standardization CEN, the different national standards organisations, such as DIN in Germany, or building trade organisations and associations. They may be made binding at a national level. In Germany, the relevant technical rules are published in official lists established by the building authorities and serve as guidelines to the tradesmen. In addition to this, there are binding legal provisions, especially relating to the vocational training of building tradesmen and to occupational safety and health.

Execution rules specify how construction products have to be assembled to form building components or entire buildings. They also define minimum qualification requirements for tradesmen and certification procedures to check compliance with the relevant standards or the technical expertise of the tradesmen.

Several stakeholders are involved in monitoring execution. Under private law, the owner or the general contractor ensures that contractual obligations are fulfilled. In addition to this, public building controls are carried out by the building authorities. These, however, are limited to infrequent spot checks. For complex or critical projects, the certified structural engineer who verified the structural design has to be involved in the monitoring process, verifying compliance with the plans and the correct execution of the construction works. The private and public stakeholders involved in the monitoring process also ensure that only construction products bearing a conformity marking are used.

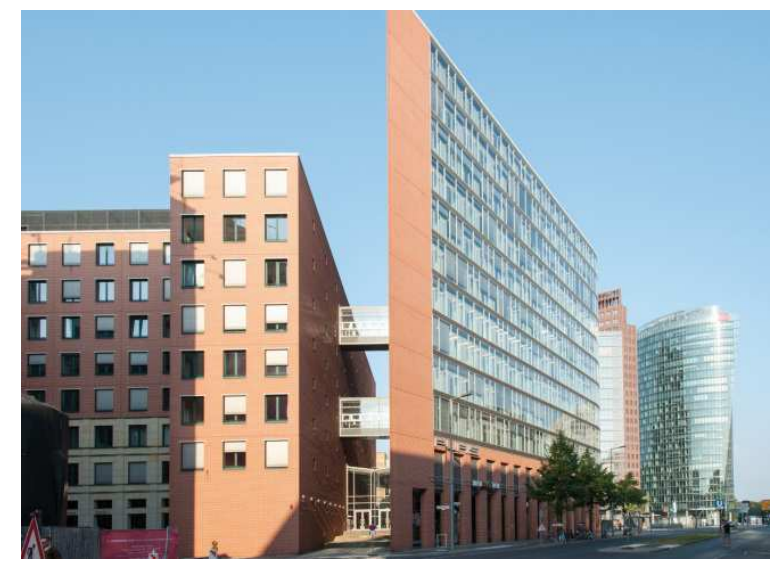

Fig. 4.Safe construction products, safe designs and safe execution guarantee safe buildings.

\section{Conclusion}

As we have said, it is not possible to guarantee absolute safety in construction. However, the measures described above have proven very effective in ensuring a high level of construction safety in Europe. Which lessons can we draw from the European experience? First of all, it can be said that it is insufficient to rely entirely on the civil liability of the manufacturer or the contractor to ensure the safety of construction works. Safety is a public good and public control measures are necessary. Secondly, even though enforcement measures are needed to ensure compliance with the legal provisions, the main focus of the public authorities should be to prevent risks,e.g. through technical assessments before marketing or verification of structural designs before execution. Thirdly, control measures should apply at different stages of the construction process and include the following: initial testing and assessment of the construction product, continuous surveillance of the manufacturing process to ensure constancy of product performance, verification of structural designs and monitoring of the execution of construction works. Finally, it must not be forgotten that construction is an activity. Therefore, proper training, qualification and information of all stakeholders involved are paramount.

\section{References}

1. Regulation (EU) No 305/2011, as amended 